\title{
sciendo
}

\section{The Relative Age Effect at the Ice Hockey World Championships (IHWC) in the years 2015-2017}

\author{
by \\ Jiř̌ Nykodým¹, Michal Bozděch², Adrián Agricola3, Jiř́ Zháněl ${ }^{2}$
}

The relative age effect (RAE) theory is based on the premise that athletes born in the first months of the calendar year have a significant probability of a higher level of physiological, morphological and psychological abilities compared to later-born athletes. The aim of our study was to verify the influence of the RAE on adult ice hockey players, specifically Ice Hockey World Championships' (IHWC) participants in the years 2015-2017 ( $n=1,200)$. Based on the chi-squared $\left(\chi^{2}\right)$ analysis, the influence of the RAE during the 2015-2017 period could not be rejected for all observed players $\left(\chi^{2}=\right.$ $54.6, p<0.01, w=0.21)$ or for all the players for particular years $(2015,2016$, and 2017; $p<0.01)$. During the monitored period (2015-2017), the RAE could not be rejected for any player's position (forward, defender, or goaltender). Based on the effect size analysis (Cohen's $w$ ), the strongest RAE was observed among goaltenders ( $w=$ $0.31)$, then forwards $(w=0.24)$ and finally defenders $(w=0.15)$. The assessment of player's positions in particular years showed statistical significance for goaltenders only in $2015\left(\chi^{2}=11.3, p<0.05\right)$. With regard to forwards, significance was confirmed for $2015\left(\chi^{2}=8.5, p<0.05\right), 2016\left(\chi^{2}=15.2, p<0.01\right)$ and $2017\left(\chi^{2}=14.3, p<0.01\right)$. Therefore, the presence of the RAE could not be rejected for all these cases. The results of the research show that members of national teams in the years 2015-2017 were players who were chronologically older, which is consistent with the results of other authors addressing the RAE.

Key words: athletic talent, birthdate, national teams, player's position.

\section{Introduction}

The relative age effect (RAE) or the influence of the birth date has been the subject of research in various areas for more than 50 years. Additionally, other names describing the same phenomenon can be found in the professional literature: Birth Date Effect (Karcher et al., 2014), Birth Quarter (Larouche et al., 2010). Due to the relative age effect (RAE) occurring most frequently in published studies, we use this particular term in this paper. The first studies on the influence of the RAE were carried out in the area of education; Green and Simmons (1962) stated that school students born in the first half of the year had better academic results than students of the same year born in the second half of the year.

In sports, the first studies focused on the RAE in ice hockey (Barnsley et al., 1985; Barnsley and Thompson, 1988). A large number of research studies have been devoted to the influence of the RAE in the National Hockey League (NHL). In one of the early studies, Barnsley et al. (1985) found that in the Western Hockey League (WHL) and the Ontario Hockey League (OHL), the number of players born in the first three months

\footnotetext{
1 - Department of Sports, Faculty of Sport Studies, Masaryk University, Brno, Czech Republic.

2 - Department of Kinesiology, Faculty of Sport Studies, Masaryk University, Brno, Czech Republic.

3 - Department of Physical Education and Sport, Faculty of Education, University of Hradec Králové, Hradec Králové, Czech Republic.
} 
of the year (Q1) was significantly higher than the number of players born in the fourth quarter of the year (Q4). In a follow-up study (1988), Barnsley and Thompson also showed a significant influence of the RAE in National Hockey League (NHL) players, while no such influence was proven in third league players. In their extensive review, Musch and Grondin (2001) also noted a significant influence of the RAE not only in NHL players, but also in lower-level competitions. The strong influence of the RAE on NHL players was explained by Barnsley and Thompson (1988) and later by Fumarco et al. (2017) as being due to the selection of athletic talent that occurs during pubescence, when players' performance is significantly affected by different levels of biological development. Gibbs et al. (2012) found that the length of sport career of ice hockey players had the opposite trend to that of the RAE; later-born players had a longer sport career than players born at the beginning of the year. Baker and Logan (2007) researched the influence of the RAE on the NHL draft and found that the date of birth (and, surprisingly, also the size of the hometown) had a substantial influence on the probability of being recruited into the NHL. Although most of the research studies on the RAE in ice hockey concentrate on men, Smith and Weir (2013) found significant predominance of women's players with an earlier date of birth in Ontario $(n=36,555)$ in the U8 U21 age categories. Additionally, in Swedish elite women's hockey league players $(\mathrm{n}=2,811)$, Stenling and Holmström (2014) found a demonstrable, significant influence of the RAE in all age categories (5 20 years) as well as in the player's positions of defenders and forwards, but not in goaltenders. A significant influence of the RAE in a group of Canadian women's ice hockey players $(n=660)$ was also found by Weir et al. (2010).

In a number of studies, the RAE is associated with the issue of talent identification in sports, which has been discussed in the professional literature since the 1970s (Hohmann and Seidel, 2003). According to Hohmann and Seidel (2003), 'athletic talent' refers to a person who has either achieved a top performance in his/her sport career (retrospective view) or who, with respect to training already performed, achieves above-average performance compared to a reference group with a similar development level and, with respect to endogenous dispositions, vs. exogenous conditions, is able to achieve top sports performance with further development (prospective view). Research addressing talent identification has been gradually focused on three areas: (1) sports medicine (heredity and genetic markers), (2) training (determining the level of characteristics affecting sports performance), and (3) seeking the limits of the physical load of the human body (Hohmann and Seidel, 2003). In many sports, talented athletes are selected according to the current level of motor preconditions (general vs. specific ones) and anthropometric features, determined mostly by tests and test batteries. A frequent problem is the fact that the level of ontogenetic development (biological age) is not taken into account, nor is the possible effect of significant differences between athletes born at the beginning, vs. at the end of the year (calendar vs. chronological age). This can be explained in the following way: while in the youth categories, the significant influence of the RAE is actively supported by various aspects (developmental gain, more significant support by coaches, better training often available to older players, strong support of parents leading to a better performance supporting motivation, etc.); for males, this condition (a higher number of earlier-born individuals) is more likely a result of the influence of the RAE in previous categories, as most of the supportive aspects disappear for males. Cobley et al. (2009), explaining the influence of the RAE, mentioned that a higher chronological age brought a higher probability of a better level of physical condition. An age difference of almost 12 months can significantly influence physical and performance differences, especially during puberty (usually an age of 1315 years in boys and 1214 in girls); chronologically older athletes have a greater probability of achieving a higher level of physical fitness earlier due to the earlier onset of puberty. In connection with a higher body height and greater body mass, early-born athletes usually also reach higher levels of strength, endurance and speed than later-born athletes, which enables them to achieve better performance, especially in high-fitness sports. These athletes are then identified through various selection processes as being above average when compared to normative data. However, it is not 
exceptional that such athletes end their sport careers after a few years of training, most often during the transition from the junior to the adult category (Cobley et al., 2009). One of the possible reasons for this is that the often mentioned advantage of their birth having been at the beginning of the year rather than at the end of the year (i.e., the influence of the RAE) later disappears. Although studies concerning the RAE in sports have been conducted for more than 30 years, coaches, clubs and federations often do not pay enough attention to this issue and do not attempt to change the traditional system of identification and selection of talent. However, during the course of ontogenesis, the talent "for something" can turn into a talent "for something totally different", or its potential will not be fulfilled at all, unless it is properly developed (Simonton, 1999). In the opinion of most of the abovementioned authors dealing with the RAE in sports, it is important to reflect on the potential influence of the RAE in the identification of athletic talents as well as on the impact on the athletes' further development and sport careers.

Relatively few published studies have addressed the influence of the RAE at the level of national teams. González-Víllora et al. (2015) studied the RAE in soccer at the UEFA European Soccer Championships (U17, U19 and U21). Sedano et al. (2015) also studied the influence of the RAE in the U17, U19, U21 (and senior category), but in female soccer players. AndradeSouza et al. (2015) researched the influence of the RAE in the FIFA World Cup Emirates (U17). The influence of the RAE on Spanish basketball national teams (from the U16 to senior team) was studied by Garcia et al. (2016). Saavedra et al. (2014) also studied the influence of the RAE in basketball: specifically, in the U17, U19 and U21 categories. Campos et al. (2016) studied the RAE in the U19, U21, and U23 men's volleyball championships and men's volleyball World Cups. The RAE in Norwegian handball national teams (youth, junior, and senior male and female teams) was presented in a study by Bjørndal et al. (2018); Wrang et al. (2018) researched the influence of the RAE in U19 and U21 national handball players in Denmark.

Only the results for junior teams are known in ice hockey (Barnsley and Thompson, in Cobley et al., 2009). Therefore, we focused our research on adult hockey players, at the level of the top "A-category" national teams in the International Ice Hockey Federation (IIHF), who had participated in the Ice Hockey World Championships (IHWC) in 2015 2017. With regard to the research problem, our aim was to determine whether there was an influence of the RAE demonstrable in all players throughout the observation period and during particular years. The other objective was to determine whether the RAE was demonstrated for particular player positions.

\section{Methods}

\section{Participants}

The study focused on the influence of the RAE in male participants of three consecutive Ice Hockey World Championships (IHWC 2015-2017) hosted by the Czech Republic (2015, Prague, Ostrava, $\mathrm{n}=398$ ), by Russia (2016, Moskva, Saint Petersburg, $n=400$ ) and jointly by Germany and France (2017, Cologne, Paris, n = 402); the total number of monitored players was 1,200 .

Research data were retrieved from http://www.mshokej.wbs.cz/ for the years 2015-17.

\section{Procedures}

The division of players into specific quarters of the year was based on the date of their birth as follows: $\mathrm{Q}_{1}$ (January through March), $\mathrm{Q}_{2}$ (April through June), $\mathrm{Q}_{3}$ (July through September), and $\mathrm{Q}_{4}$ (October through December). The analysis of the research data was carried out in connection with the formulation of the research problem and assessed the RAE (1) in all players throughout the whole observation period; (2) in all players in particular years; and (3) according to the player's position (forward, defender, or goaltender).

\section{Statistical Analysis}

To assess the match of the theoretical (expected) frequency distribution and empirical (observed) frequency distribution, we used the goodness-of-fit variant of the chi-squared test $\left(\chi^{2}\right)$ because of the large size of the data set; data were analysed with the use of an online program available at

https://www.socscistatistics.com/tests/goodnessof fit/Default2.aspx. The theoretical (expected) 
frequency distribution was $\mathrm{Q}_{1}=90 / 365.25(24.6 \%)$; $\mathrm{Q}_{2}=91 / 365.25(24.9 \%) ; \mathrm{Q}_{3}=92 / 365.25(25.2 \%) ; \mathrm{Q}_{4}=$ $92 / 365.25(25.2 \%)$. The next step was to calculate the effect size (Cohen's $w$ ); based on Cohen (1988), the effect size was interpreted as small $(w=0.10)$, medium $(w=0.30)$ or large $(w=0.50)$. The research data were processed using STATISTICA 10 Microsoft Excel software.

\section{Results}

The influence of the RAE on players for particular years and throughout the monitored period (20152017)

Figure 1 shows an overview of the distribution of absolute frequencies of the research data for each quarter of the year $\left(\mathrm{Q}_{1}-\mathrm{Q}_{4}\right)$ for 2015-2017.

It is clear from Figure 1 that the highest absolute frequencies were always found in $\mathrm{Q}_{1}$ (highest frequency in 2016, $\mathrm{n}=138$ ), the second highest frequencies were always found in $\mathrm{Q}_{3}$ (highest frequency in 2015, $\mathrm{n}=105$ ), and the lowest absolute frequencies were found in $\mathrm{Q}_{4}$ (lowest frequency in 2016 and 2017, $\mathrm{n}=78$ ). The distribution of absolute frequencies in particular quarters had a sinusoidal character. The betweenyear difference between the absolute frequencies in particular quarters $\left(\mathrm{Q}_{1}-\mathrm{Q}_{4}\right)$ was relatively small with regard to the range of the group $(n=1,200)$, the highest being found in the first (diff $=12)$ and in the third quarter (diff $=9$ ) of the year.

Table 1 contains the values of the relative frequencies for each year for particular quarters as well as the relative frequencies for the whole observed period (2015-2017). The table also presents tests of significance between the theoretical distributions and the distributions of frequencies in the research (empirical) data, as calculated by the chi-squared test $\left(\chi^{2}\right)$.

The results shown in Table 1 make it clear that statistically significant differences between the expected and observed distributions of relative data frequencies were found in all cases. Therefore, the influence of the RAE cannot be rejected for the groups of players either for particular years or throughout the monitored period (2015-2017). Given that the higher chisquared $\left(\chi^{2}\right)$ value suggest a greater lack of match between the expected and observed distributions of frequencies, we can conclude that the greatest lack of match, i.e., the greatest RAE, was found for the group consisting of all players during the observation period $(2015-2017)\left(\chi^{2}=54.6\right)$. The effect size was small in all cases ( $w=0.19-0.24)$.

\section{The Influence of the RAE on player's positions}

The distribution of absolute frequencies of the research data in particular quarters $\left(\mathrm{Q}_{1}-\mathrm{Q}_{4}\right)$ during 2015-2017 for individual player's positions (goaltender, defender and forward) is shown in Figure 2.

Logically, the group of goaltenders was relatively small $(n=142)$, and this is reflected in great between-year differences of absolute frequencies, especially in $\mathrm{Q}_{1}$ and $\mathrm{Q}_{2}(\mathrm{diff}=7)$. The highest absolute frequencies were achieved in $\mathrm{Q}_{1}$, then in $\mathrm{Q}_{3}$; similarly, for the whole group (Figure 1), the distribution in particular quarters of the year had a sinusoidal character. The highest absolute frequencies were found in $\mathrm{Q}_{1}$ and $\mathrm{Q}_{3}$; lower frequencies were found in $\mathrm{Q}_{2}$ and $\mathrm{Q}_{4}$.

In the group of defenders $(n=382)$, again, relatively great between-year differences in absolute frequencies were found in $\mathrm{Q}_{1}$ and $\mathrm{Q}_{2}$ (diff =9); the distribution of frequencies in particular quarters again had a sinusoidal character, with the highest frequencies found in $\mathrm{Q}_{1}$ and $\mathrm{Q}_{3}$ and lower frequencies in $\mathrm{Q}_{2}$ and $\mathrm{Q}_{4}$.

The distribution of absolute frequencies in the largest group of forwards $(n=676)$ had a somewhat different character; between-year differences were relatively small, with the greatest difference in $\mathrm{Q}_{2}(\operatorname{diff}=5)$. The overall character of the frequency distribution had a downward trend from $Q_{1}$ to $Q_{4}$, in contrast to the distributions for goaltenders and defenders.

The tests of significance between the expected and observed frequency distributions (i.e., the RAE) for particular player's positions are shown in Tables 2, 3 and 4.

The results in Table 2 show that the influence of the RAE on the group of goaltenders could not be rejected in $2015\left(\chi^{2}=11.3\right)$ and throughout the monitored period 2015-2017 $\left(\chi^{2}=\right.$ 13.7). The RAE did not have an influence on goaltenders in $2016\left(\chi^{2}=7.1\right)$ and in $2017\left(\chi^{2}=0.6\right)$. The effect size revealed a small $(w=0.11)$ to medium $(w=0.49)$ effect.

As seen from the results shown in Table 3 , the RAE did not have an influence on defenders in 2015 and 2016, as there were no statistically significant differences found between the 
expected and observed frequency distributions. The influence of the RAE could not be rejected for the 2017 group $(p=0.04)$ and all defenders throughout 2015-2017 $(p=0.03)$. The effect revealed a small effect $(w=0.10-0.25)$.

Statistically significant differences were shown between the expected and observed frequency distributions for forwards in 2015, 2016 and 2017 and throughout the observation period (2015-2017), which had the highest chi-squared value $\left(\chi^{2}=39.9\right)$. Thus, the RAE could not be rejected in those periods. The effect size was small $(w=0.19-0.26)$.

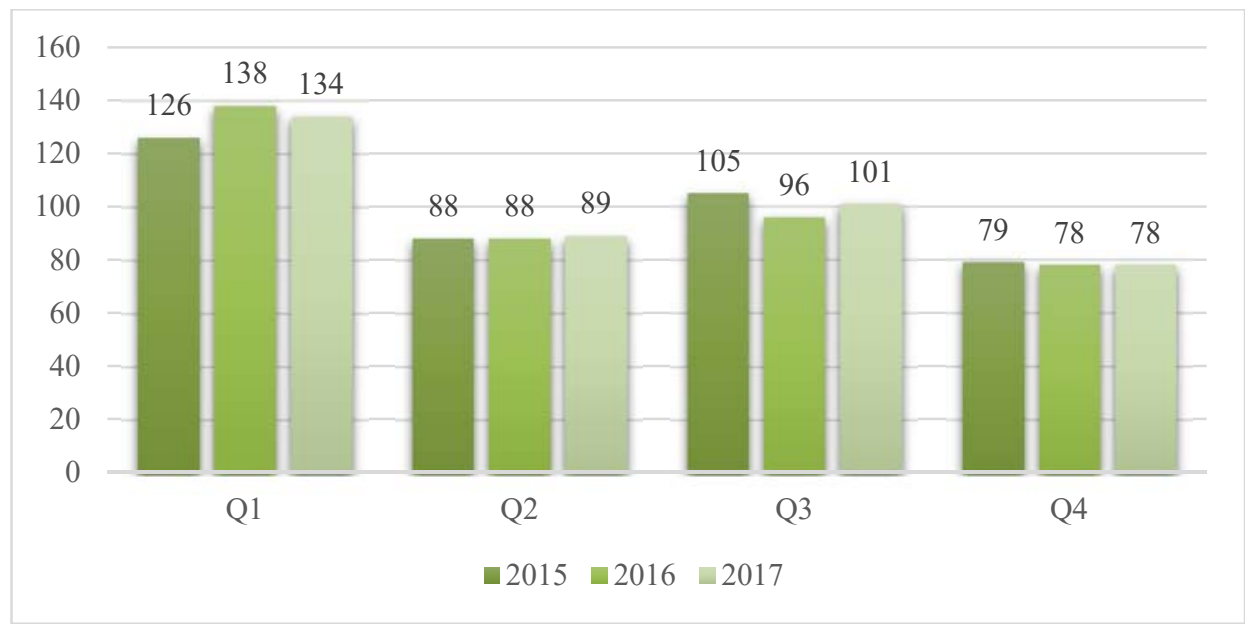

Figure 1

Overview of the distribution of absolute frequencies of players for 2015-2017

Table 1

Distribution of the relative data frequencies from 2015-2017

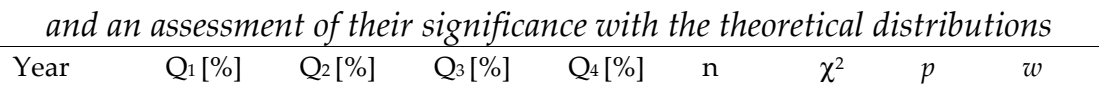

\begin{tabular}{lllllllll}
\hline 2015 & 31.7 & 22.1 & 26.4 & 19.8 & 398 & 14.0 & 0.00 & 0.19 \\
2016 & 34.5 & 22.0 & 24.0 & 19.5 & 400 & 22.7 & 0.00 & 0.24 \\
2017 & 33.3 & 22.1 & 25.1 & 19.5 & 402 & 19.1 & 0.00 & 0.22 \\
$2015-17$ & 33.2 & 22.1 & 25.2 & 19.5 & 1,200 & 54.6 & 0.00 & 0.21
\end{tabular}

Explanatory notes: $\mathrm{n} . .$. size of the group; $\chi^{2} \ldots$ chi-squared;

$p \ldots$...significance level; $w \ldots$..effect size 


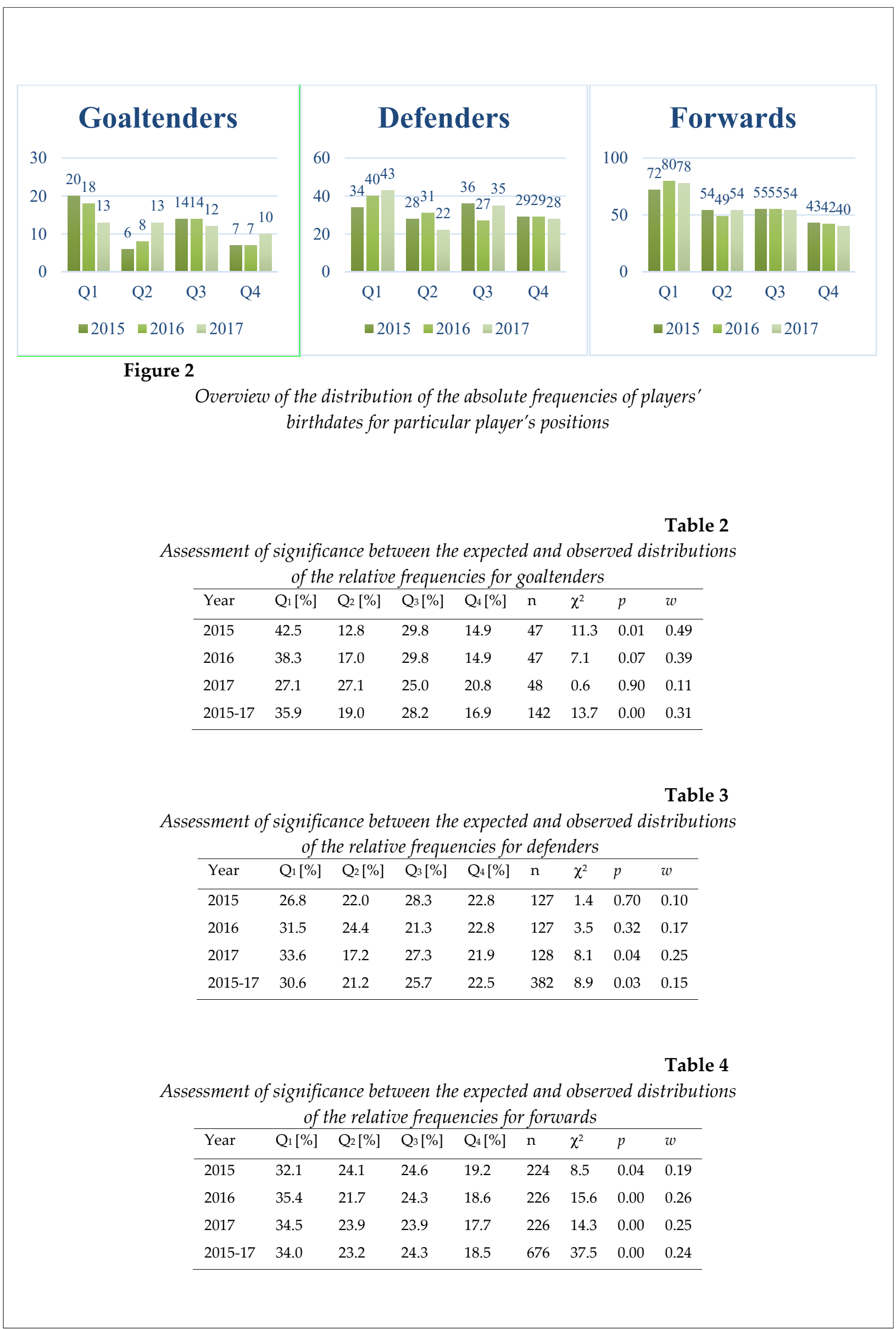




\section{Discussion}

The aim of this study was to determine the influence of the RAE on a large group of hockey players, participants of the IHWC $(\mathrm{n}=$ 1,200) throughout 2015 2017; as mentioned above, there is no scientific study focusing on the RAE at the national level for adult hockey players.

With regard to the results of some studies (reported in the synthesis of findings) concerning the RAE in various sports, it can be logically assumed that the RAE should be more pronounced among the members of national teams than among players at the club level because the best performing athletes are selected for national teams. The results of Gibbs et al. (2012) do not confirm this theory, which could be caused by individual performance conditions (physiological, morphological and psychological) gradually equalized with age. Additionally, during the long-term training process, selection pressure weakens, and the influence of the RAE (according to the above-mentioned authors) decreases in adulthood.

Our findings, however, have shown that the RAE cannot be rejected in the groups of all players either in particular years $(2015,2016$, or 2017) or for the whole observed period of 2015 2017. The results are therefore fully consistent with the conclusions of some of the data found in NHL players by Barnsley et al. (1985) in the 1982/83 season $(\mathrm{n}=715$ : Q1 $=32.0 \%$, $\mathrm{Q} 2=29.8 \%, \mathrm{Q} 3=21.9 \%$, and Q4 $=16.2 \%$ ) as well as by Addona and Yates (2010) from 19702009 (n = 6,391: Q1 = 29.45\%, Q2 = 26.63\%, Q3 = 22.91\%, and Q4 $=21.1 \%$ ), Fumarco et al. (2017) from $20082016(\mathrm{n}=4,447: \mathrm{Q} 1=29.99 \%, \mathrm{Q} 2=28.2 \%$, Q3 $=22.03 \%$, and $\mathrm{Q} 4=19.76 \%$ ), Lavoie et al. (2015) from 2005-2011 ( $\mathrm{n}=13,982: \mathrm{Q} 1=47.3 \%, \mathrm{Q} 2=$ $27.1 \%$, Q3 $=17.2 \%$, and Q4 $=18.5 \%$, and Delorme et al. (2009) in elite French hockey players from 2005 to $2006(\mathrm{n}=248 ; \mathrm{Q} 1=34.27 \%$, Q2 = 21.77\%, Q3 $=23.79 \%$, and $Q 4=20.16 \%$ ).

The most important and critical period in hockey players' careers is (similarly to other team sports) the transition from the junior to the adult men category. As demonstrated by Hancock et al. (2013) for a large group of Canadian juniors aged $1517(\mathrm{n}=25,008 ; \mathrm{Q} 1=26.05 \%, \mathrm{Q} 2=28.55 \%$, Q3 = $24.66 \%$, and $\mathrm{Q} 4=20.75 \%$ ), the RAE in junior categories is lower than in schoolchildren categories, but it is still significant. Additionally, for this reason, earlier-born individuals more often make it to the adult men category; however, the transition is often successfully handled by only several individuals, among whom the representation of earlier-born individuals is quite significant. If players for the national team are then selected from clubs, it is logical that even there, the representation of players born at the beginning of the calendar year will be significantly higher than in the clubs. Therefore, the major difference, compared to youth selection, is that adult players are no longer selected on the basis of the advantage of earlier birth, but the high frequency of players born earlier is based on the fact that they are already selected from groups (clubs) containing a high number of chronologically older players (Brazo-Sayavera et al., 2018; Delorme et al., 2013). However, it is important to note that these conclusions are more evident in males than in females (Delorme, 2014; Delorme et al., 2010).

Based on the effect size values (w), it is evident that the strongest influence of the date of birth in the observed years (2015-2017) was found for goalkeepers $(\mathrm{w}=0.31$, effect size $=$ medium $)$, then forwards $(\mathrm{w}=0.24$, effect size $=$ small $)$ and finally defenders $(\mathrm{w}=0.15$, effect size $=$ small $)$. It is quite complicated to identify the main reason for the stronger RAE in goaltenders; for example, the anthropometric characteristics are inconclusive, and the values of average body height and body weight are similar with forwards $(-1.47 \mathrm{~cm}$ and $+2.03 \mathrm{~kg}$, respectively) and defenders $(+0.33 \mathrm{~cm}$ and $+4.35 \mathrm{~kg}$, respectively). Additionally, there was only a small difference in the average body height of the Q1 goaltenders $(186.08 \mathrm{~cm})$ compared to the goaltenders in Q2 ($1.52 \mathrm{~cm}), \mathrm{Q} 3(-1.07 \mathrm{~cm})$ and Q4 $(-1.00 \mathrm{~cm})$. Schorer et al. (2015) reported that there are countless factors influencing the development of the RAE, e.g., family, coaches, scouts, hometown size or other social, economic and geographical conditions. Many other authors emphasize the influence of anthropometric factors (body height and body weight) and the influence of biological age, in particular. This has been proven (mainly in adolescents), for example, in alpine skiing (Müller et al., 2016), handball (Camacho-Cardenosa et al., 2018), soccer (Práxedes et al., 2017; Towlson et al., 2017) and ice hockey (Lavoie et al., 2015).

Relatively few studies concerning the 
players' position were published; Lavoie et al. (2015) showed that in fifteen-year-old Canadian juniors, the RAE cannot be rejected for forwards $(\mathrm{n}=245,2=115.74)$ and defenders $(\mathrm{n}=141,2=$ 45.41), while for goaltenders $(n=50,2=2.64)$, the influence could be rejected. Similar results were published by Weir et al. (2010), who demonstrated that in Canadian women's hockey players, the RAE could not be rejected for defenders and forwards, although could be rejected for goaltenders.

The different influence of the RAE on particular player positions may also be due to tactical and technical assumptions necessary for that position. Therefore, the finding that defenders are taller than forwards (Triplett et al., 2018) is consistent with the requirements for a given player's position not only in ice hockey, but also in soccer (Gil et al., 2007).

\section{Conclusions}

The analysis of the group of hockey players $(n=1,200)$ who participated in the Ice Hockey World Championships (IHWC) from 20152017 showed that the RAE cannot be rejected for the entire group of players for the whole observed period (2015 2017); also it cannot be rejected for the entire group of players for the particular years 2015, 2016 and 2017.

The assessment of the RAE for individual player's positions showed that results were partially influenced by the different sizes of the sub-groups for goaltenders $(\mathrm{n}=142)$, defenders $(n=382)$ and forwards $(n=676)$. It was proven that the influence of the RAE cannot be rejected for the entire observed period (2015 2017) for any player's position; based on the results of the chisquared test, the strongest effect was found in forwards, but we also have to take into consideration the size of the monitored groups. Based on the effect size analysis, the strongest effect was observed for goaltenders and the lowest for defenders.

The assessment of the influence on player's positions for particular years showed that the RAE in goaltenders could not be rejected only for 2015; the RAE was rejected in 2016 and 2017. The RAE in defenders was rejected for the years 2015 and 2016, but it could not be rejected for 2017. The RAE in forwards could not be rejected for all the observed years (2015, 2016 and 2017).

With regard to the results of this study, it can be stated that chronologically older players (i.e., those born at the beginning of the year) were selected demonstrably more often for national ice hockey teams. Our recommendation for practice is as follows: the issue of the RAE and the possible consequences of it for the sporting careers of young athletes should be considered in training programmes by coaches and sports managers; it is also suggested that parents of children participating in sports should learn about the RAE.

\section{Acknowledgements}

This publication was written at the Masaryk University as part of the project "Diagnostics of the level of sport-specific motor preconditions in the context of age, somatic, gender and lateral asymmetries in sport" number MUNI/A/ 1087/2017 with the support of the Specific University Research Grant, as provided by the Ministry of Education, Youth and Sports of the Czech Republic in the year 2018.

\section{References}

Addona V, Yates P. A closer look at the relative age effect in the national hockey league. J Quant Anal Sport, 2010; 6: 1227-1227

Andrade-Souza VA, Moniz F Teoldo I. Relative age effect in FIFA U17 Emirates 2013 World Cup: analysis of players who effectively participated in the matches. Motriz, 2015; 21: 403-406

Baker J, Logan, AJ. Developmental contexts and sporting success: birth date and birthplace effects in national hockey league draftees 2000-2005. Brit J Sport Med, 2007; 41: 515-517

Barnsley R, Thompson A, Barnsley P. Hockey success and birthdate: the relative age effect. Cahper J, 1985; 51 : $23-28$ 
Barnsley R, Thompson A. Birthdate and success in minor hockey: the key to the NHL. Can J Behav Sci, 1988; 20: $167-176$

Delorme N. Do weight categories prevent athletes from relative age effect? J Sports Sci, 2014; 32: 16-21

Bjørndal CT, Luteberget LS, Till K, Holm S. The relative age effect in selection to international team matches in Norwegian handball. Plos One, 2018; 13: e0209288

Camacho-Cardenosa A, Camacho-Cardenosa M, González-Custodio A, Martinéz-Guardado I, Timón R, Olcina G, Brazo-Sayavera J. Anthropometric and Physical Performance of Youth Handball Players: The Role of the Relative Age. Sports, 2018; 6: 1-10

Campos FAD, Stanganelli LCR, Rabelo FN, Campos LCB, Pellegrinotti ÍL. The relative age effect in male volleyball championships. Int J Sports Sci, 2016; 6: 116-120

Cobley S, Baker J, Wattie N, McKenna J. Annual Age-Grouping and Athlete Development. Sports Med, 2009; 39: 235-256

Cohen J. Statistical power analysis for the behavioural sciences (2nd ed.). Hillsdale, NJ: Erlbaum; 1988

Delorme N, Boiché J, Raspaud M. The Relative Age Effect in Elite Sport. Res Q Exercise Sport, 2009; 80: 336344

Fumarco L, Gibbs BG, Jarvis JA, Rossi G. The relative age effect reversal among the National Hockey League elite. Plos One, 2017; 12: 1-17

García A, Jiménez Sáiz S, Lorenzo Calvo A, Díez-Vega I. Influence of chronological age in the selection of players into the national basketball teams. Rev Psicol Deporte, 2015; 24: 27-30

Gibbs B, Jarvis J, Dufur M. The rise of the underdog? The relative age effect reversal among Canadian-born NHL hockey players: A reply to Nolan and Howell. Int Rev Sociol Sport, 2012; 47: 644-649

Brazo-Sayavera J, Martínez-Valencia MA, Müller L, Andronikos G, Martindale RJJ. Relative age effects in international age group championships: A study of Spanish track and field athletes. Plos One, 2018; 13: e0196386

Gil SM, Gil J, Ruiz F, Irazusta A, Irazusta J. Physiological and anthropometric characteristics of young soccer players according to their playing position: relevance for the selection process. J Strength Cond Res, 2007; 21: 438-445

González-Víllora S, Pastor-Vicedo JC, Cordente D. Relative age effect in UEFA championship soccer players. J Hum Kinet, 2015; 47: 237-248

Green DR, Simmons SV. Chronological age and school entrance. Elem School J, 1962; 63: 41-47

Hancock DJ, Ste-Marie DM, Young BW. Coach Selections and the Relative Age Effect in Male Youth Ice Hockey. Res Q Exercise Sport, 2013; 84: 126-130

Hohmann A, Seidel I. Scientific aspects of talent development. Int J Phys Edu, 2003; 4: 9-20

Karcher C, Ahmaidi S, Buchheit M. Effect of birth date on playing time during international handball competitions with respect to playing positions. Kinesiology, 2014; 46: 23-32

Larouche R, Laurencelle L, Grondin S, Trudeau F. Influence of birth quarter on the rate of physical activities and sports participation. J Sport Sci, 2010; 28: 627-631

Lavoie F, Laurencelle L, Grondin S, Trudeau F. Temporal plasticity of the relative age effect in ice hockey: The case of elite minor players in Québec. Int J Appl Sport Sci, 2015; 27: 14-25

Müller L, Müller E, Hildebrandt C, Raschner C. Biological Maturity Status Strongly Intensifies the Relative Age Effect in Alpine Ski Racing. Plos One, 2016; 11: e0160969

Musch J, Grondin S. Unequal Competition as an Impediment to Personal Development: A Review of the Relative Age Effect in Sport. Dev Rev, 2001; 21: 147-167

Práxedes A, Moreno A, García-González L, Pizarro D, Del Villar F. The relative age effect on soccer players in formative stages with different sport expertise levels. J Hum Kinet, 2017; 60: 167-173

Saavedra M, Gutiérrez Aguilar Ó, Fernández Romero JJ, Fernandéz Lastra D, Eiras Oliveira G. Relative age effect in lower categories of international basketball. Int Rev Sociol Sport, 2014; 49: 526-535

Sedano S, Vaeyens R, Redondo JC. The relative age effect in Spanish female soccer players. Influence of the competitive level and a playing position. J Hum Kinet, 2015; 46: 129-137

Schorer J, Cobley S, Bräutigam H, Loffing F, Hütter S, Büsch D, Wattie N, Helsen W, Baker J. Developmental contexts, depth of competition and relative age effects in sport: A database analysis and a quasiexperiment. Psychol Test Assess Model, 2015; 57: 126-143 
Simonton DK. Talent and its development: An emergenic and epigenetic model. Psychol Rev, 1999; 106: 435457

Smith KL, Weir PL. An examination of the relative age effect in developmental girls' hockey in Ontario. High Abil Stud, 2013; 24: 171-184

Stenling A, Holmström S. Evidence of Relative Age Effects in Swedish Women's Ice Hockey. Talent Dev Excell, 2014; 6: 31-40

Towlson C, Cobley S, Midgley AW, Garrett A, Parkin G, Lovell R. Relative Age, Maturation and Physical Biases on Position Allocation in Elite-Youth Soccer. Int J Sports Med, 2017; 38: 201-209

Delorme N, Radel R, Raspaud M. Relative age effect and soccer refereeing: A 'Strategic Adaptation' of relatively younger children? Eur J Sport Sci, 2013; 13: 400-406

Triplett AN, Ebbing AC, Green MR, Connolly CP, Carrier DP, Pivarnik JM. Changes in collegiate ice hockey player anthropometrics and aerobic fitness over 3 decades. Appl Physiol Nutr Metab, 2018; 43: 950-955

Delorme N, Boiché J, Raspaud M. Relative Age Effect in Elite Sports: Methodological Bias or Real Discrimination? Eur J Sport Sci, 2010; 10: 91-96

Weir PL, Smith KL, Paterson Ch, Horton S. Canadian Women's Ice Hockey - Evidence of a Relative Age Effect. Talent Dev Excell, 2010; 2: 209-217

Wrang CM, Rossing NN, Diernæs RM, Hansen CG, Dalgaard-Hansen C, Karbing DS. Relative age effect and the re-selection of Danish male handball players for national teams. J Hum Kinet, 2018; 63: 33-41

\section{Corresponding author:}

\section{Adrián Agricola}

Department of Physical Education and Sport

Faculty of Education, University of Hradec Králové

Rokitanského 62/26, Hradec Králové, 500 03, Czech Republic

Phone: +420 723762201

E-Mail: adrian.agricola@gmail.com 